\title{
Recent Advancements in Geopolymer Concrete using Class-F and Class-C Fly Ash
}

\author{
B.Vijaya Prasad, P. D Arumairaj.
}

\begin{abstract}
In recent decades, to depreciate usage of ordinary Portland cement(OPC) for the construction industry, enormous research work is going on high rich Al-Si waste materials as source material for producing Geopolymer concrete(GPC). In this paper, a review is done in three ways namely A) To study the short term and long term characteristics of various types of fly ash based Geopolymer concrete (GPC) and B) Development of Hybrid Geopolymer concrete, by partial replacement of fly ash with high calcium materials like Cement, slag and . C) Field applications of Geopolymer concrete (GPC); The research papers published are thoroughly reviewed to identify the research gap. Keywords-Class-C Flyash (FA-C), Class-F Flyash (FA-F), Ground granulated blast furnace slag(GGBS), Alkaline activators(A-A), Alumino silicate(Al-Si).
\end{abstract}

\section{NTRODUCTION:}

OPC is one in all the foremost largely used construction material within the world for making Concrete. Throughout manufacture of cement a large quantity of $\mathrm{CO} 2$ is released into atmosphere .Each one ton production of OPC results in one ton of carbon dioxide $\left(\mathrm{CO}_{2}\right)$ that considerably contributes to greenhouse emissions. This is based on production reports in (Olivier et al 2015). To decreases $\mathrm{CO}_{2}$ emissions during the manufacture of cement, a French materials scientist (Joseph Davidovits 1994) invented the new alternative to cement term "GP" in 1979.

The Geopolymer (GP) materials is an inorganic rich $\mathrm{Al}-\mathrm{Si}$ compound, manufactured from materials of the geological source or from by-product materials like GGBS, Metakaolin(Mk), rice husk ash(RHA) and 3 different kinds of fly ash(FA) like FA-C and FA-F to create Geo polymerization (Davidovits1994; Hardjito and Rangan 2005) these rich Al-Si material have to react with strong alkali solutions like Sodium hydroxide( $\mathrm{NH})$, Potassium hydroxide $(\mathrm{KH})$, and Sodium silicate (NS) or Potassium silicate (KS) in oven-dry curing and steam curing at 60 to 90 ${ }^{0}$ C. (Wallah and Rangan 2006). The 2 common primary kinds of garbage materials widely utilized as source material are GGBS and FA following A-A as GP binder. AA systems are generally classified into two classes supported the chemical composition of precursor reactant bulk: $\mathrm{Ca}-\mathrm{Si}$ and Al-Si systems ( $\mathbf{L i}$ et al. 2010)A-A of FA-C and GGBS leads to a $\mathrm{Ca}-\mathrm{Si}$ system, whereas MK silica fume, kaolinite clay, and FA-F area system common precursor reactants of an $\mathrm{Al}-\mathrm{Si}$ system. All system involves different reaction mechanisms and manufacture gels (reactant products) of different characteristics. The $\mathrm{Ca}-\mathrm{Si}$ system undergoes a complex reaction that involves hydration of $\mathrm{CaO}$ within the presence of $\mathrm{Al}_{2} \mathrm{O}_{3}$ to form an aluminum-modified calcium silicate hydrate $[\mathrm{C}-\mathrm{A}-\mathrm{S}-\mathrm{H}]$ gel as a significant binding part. (Li et al. 2010; Pattanapong et al 2014; Pradip and Prabir 2015; William Gustavo et al 2016;Najif et al 2018; Elchalakani et al 2018; Hilal El-Hassan and Said Elkholy 2019). On the other hand, the chemical process of an Al-Si system involves the dissolution of $\mathrm{SiO} 2$, coagulation, and an extremely exothermic condensation reaction followed by crystallization to create zeolite like polymers, by a 3-dimensional sodium Alumino-Silicate hydrate $(\mathrm{N}-(\mathrm{A})-\mathrm{S}-\mathrm{H})$ GP gel as a significant binding phase (Li et al. 2010). A mixed system created from alkali activation of a combination of fly ash and high metallic element materials begins to coexistent $\mathrm{C}-(\mathrm{A})-\mathrm{S}-\mathrm{H}$ and $\mathrm{N}-\mathrm{A}-\mathrm{S}-\mathrm{H}$ gels with a fascinating higher level of crosslinking (Li et al. 2010; Pattanapong et al 2014; Pradip and Prabir 2015; William Gustavo et al 2016; Najif et al 2018; Elchalakani et al 2018; Hilal El-Hassan and Said Elkholy 2019). The homogenized system has been reported to show superior mechanical and durability performance in resisting sodium and magnesium sulfate attack in comparison with standard portland cement concrete (Pattanapong et al 2014; Pradip and Prabir 2015; William Gustavo et al 2016; Najif et al 2018; Elchalakani et al 2018; Hilal and Elkholy 2019).

\section{LITERATURE REVIEW}

A. Class-F Fly ash based Geopolymer concrete:

Aleem and Arumairaj (2012) In this paper, a GPC is prepared by using M-sand as fine aggregate to seek out an optimum mix design and an investigation is made with Concrete cubes and cured with steam curing for 1 day and tested after 7 days and 28 days. The obtained optimum mix design is $1: 1.5: 3.3$ with A-A to FA-F ratio of 0.35 , and it was observed that early and high strength was found with the GPC mix.

Raijiwala and patil (2011) A comparative study is done on the different properties of GPC using FA-F, with different mix proportions and $\mathrm{A}-\mathrm{A}$ used are $\mathrm{KH}, \mathrm{NH}$ solution and concluded that as compared to OPC concrete (M25 and M45) the Compressive strength for Pull Out strength of GPC improved by 1.5 times more, the Split Tensile Strength of GPC improved by1.45 times more and Flexural Strength improved by1.6 times more.

B.Vijaya Prasad Research Scholar, Department of Civil Engineering, Karunya Institute of Technology \&Science Coimbatore, Tamilnadu, India. Email: b.vprasad104@gmail.com.

P. D Arumairaj. Professor, Department of Civil Engineering, Karunya Institute of Technology \&Science Coimbatore, Tamilnadu, India.

Email: arumairajcbe@gmail.com 


\section{Recent Advancements in Geopolymer Concrete using Class-F and Class-C Fly Ash}

But in Durability studies, as compared to OPC concrete the weight loss of GPC is 10 times more and for $12 \mathrm{M} \mathrm{KH}$ solution, a very moderate strength is observed.

Benny and George Mathew(2012) An Experimental study on the influence of the aggregate content on the engineering properties including other parameters of engineering properties such as curing temperature, duration of curing, NS/NH ratio in GPC. It was noted that GPC with total aggregates of $70 \%$ by volume, ratio of fine aggregates to the total aggregate of $0.35,10 \mathrm{M}$, with 2.5 of $\mathrm{NS} / \mathrm{NH}$ ratio and 0.55 of alkali to FA ratio when cured for $24 \mathrm{~h}$ at $100{ }^{\circ} \mathrm{C}$ give $96.4 \%$ cube strength of 28days in 7 days.

Aleem et Al(2013). An experimental study is done by replacing the total normal sand by Manufacturing Sand (M Sand) having more amount of Silica. It will activate the inorganic molecules producing good bonding between the materials in the GPC. The compound formation has been verified by physical methods and Microstructural analysis. It was observed that Making of GPC with M-sand showed that a chemical reaction is occurring and a new compound was formed.

Ali A et Al (2016) An experimental work is done by adding extra water content, plasticizer, NH molarity, an alkaline solution to FA ratio and NH: NS ratio on FA based GPC. It was observed that Extra water develops workability but decreases other properties and with plasticizers the workability raised by $15 \%$ but other properties decrease by $25 \%$. Increasing NH to NS ratio harms GPC properties.

Lateef Sayed Ali et Al (2016) An experimental work is done by using two activating solutions to find the compressive strength of FA GPC: 1) With a combination of water, $\mathrm{NH}$ and silica fume; and 2) With a combination of water, NH solution and NS. It was observed that in curing condition, the activating solution like silica fume is utilized for making GPC is not significantly influencing the compressive strength when compared by the use of NS.

Ernesto et Al (2016) An investigation is done by the consequence of sand/fly ash (S/FA) ratios on the compressive and tensile properties of GP mortar. it was observed that Strengths shows a reducing trend with increasing S/FA ratio.

Chamila et Al (2018) A systematic experimental study was undertaken to manufacture Geopolymer coarse aggregate (GPA) using FA-F. To investigate a viable manufacturing method for GPA production and the consideration of essential durability characteristics and mechanical properties of GPA concrete is examined up to 90 days. GPA made out of GPC with $50 \mathrm{Mpa}$ by from a solid cylindrical piston, used in the manufacture of GPA concrete produced 37Mpa compressive strength. The GPA concrete thus prepared exhibits low water and air permeability intimating that the material is a high-quality concrete. Such concrete was observed to have a dense pore structure.

Madhu et Al (2018) An experimental study is made to manufacture lightweight GPC by partial replacement of normal weight aggregate by three various types of the lightweight aggregate (LEA) namely Pumice, LECA, and Sint aggregate with $14 \mathrm{M} \mathrm{NH}$. The percentage of replacement of standard weight aggregate varies from $0 \%$ to $20 \%$ in each case. Fresh and Hardened properties of lightweight GPC are assessed, by carrying slump cone, compressive, split tensile and flexural strength tests are cured under room temperature. It was observed that Pumice, LECA when compared to the natural coarse aggregates the
Sint aggregate have higher water saturation which affects the workability. Soaking of aggregates before mixing shows that LWA GPC with Sint aggregate shows less water absorption than that of Pumice and LECA

Manoj et Al (2017) GP and control concrete are compared and evaluated in terms of torsion. Experimental work is done with four GP beams and four control concrete beams including and not including fibers. it was observed that compared to control concrete the ultimate torque resistance of GPC is higher. It is noticed that with steel fibers volume of $1 \%$ improves torsional strength and stops sudden brittle failure. It shows the cracking torsional resistance of the control beam is less compared to the GPC steel fiber beams. Pradip Nath et al (2017) An experimental work is done on the properties of blended FA-F GPC cured in room temperature. GPC was generated using FA-F with a small percentage of the replacement of FA with GGBS, hydrated lime, and Portland cement to improve an early age. It was observed that the density of hardened GPC mixtures is similar to that of normal weight OPC concrete, As compared to Portland cement concrete Addition of additives improved the mechanical strengths. Compare to Portland cement concrete the Elastic modulus of GPC less.

Venu and Gunneswara (2018) An experimental work is carried out on cubes and prisms and cylindrical GPC specimens as per the IS codebook to study the stress-strain behavior along with the flexural, compressive and split tensile strengths for the GPC20, GPC40, and GPC60 grades at $8 \mathrm{M} \mathrm{NH}$ and alkaline liquid ratio in a ratio of 2.5 were used. It was observed that at ambient curing condition of FA and GGBS based GPC showing good mechanical properties and stress-strain relations. The elastic modulus was significantly varied with increases in the grade of the concrete. GPC with compressive strength range of $20 \mathrm{MPa}$ to $60 \mathrm{MPa}$, an equation was introduced to determine the modulus of elasticity $\mathrm{E}=[4.26 \mathrm{C} 2-111.74 \mathrm{C}+10365] * 10-3$ $\mathrm{GPa}$, where $\mathrm{C}$ is compressive strength of GPC

Chen Yang and Gupta (2018) An investigation was made with a combination of $\mathrm{KH}$ and $\mathrm{KS}$ were used as the A-A to initiate the GeoPolymerization reaction and effect of the concentration of $\mathrm{KH}$ and the ratio of $\mathrm{KS}$ to $\mathrm{KH}$ ratio on the compressive strength was observed, with water immersion curing method. The concrete specimens were first cured at $60^{\circ} \mathrm{C}$ for 1 day, followed by ambient curing until testing. It was observed that GPC activated with $14 \mathrm{M} \mathrm{KH}$ solution with the KS/KH of 2.0 exhibited the highest strength. This study also proposes an NDT method for the prediction of compressive strength. By using multiple regression techniques, an accurate predictive relationship was established between the compressive strength and the longitudinal resonant frequency.

Salmabanu et al (2018) An investigation is done on partial replacement of river sand by waste rubber tire fibres for producing FA based GPC and studied density, compressive strength, and weight Changes. The microstructure of rubberized FA based GPC and conventional GPC at ambient curing and after elevated temperatures for 2 hours is examined. It was observed that at elevated temperatures compared to conventional GPC the deterioration in strength is more for rubberized GPC due to the presumable mismatch among the coefficients of thermal expansion of the essential elements. 
Wei Li et al (2018) An investigation is made by adding $2 \%$ by volume PVA fibers in GP mortar to study the transport characteristics, mechanical characteristics, Flexural characteristics, toughness, including water sorptivity and stability to the penetration of chloride, cured at 7, 14 and 28 days and compared with plain GP mortar and control mortar. It was observed that a gel is formed by name Gismondine.PVA fiber that can enhance the flexural, toughness due to the bridging impact at cracks. Compare to plain GP the Water sorptivity was seen to be lower for PVA fiber GP and the critical diameter of the pore was bigger than Portland cement mortar because water glass is very less in A-A.

Kirubajiny et Al (2018) A durability test done by the same exposure environment on GPC culverts and Control concrete to find the effect of carbonation, permeation properties, and pore size distribution. It is observed that compared to the control concrete the GPC has lower carbonation resistance and there are no significant variations that happened between laboratory-prepared carbonated and un carbonated GPC specimens, therefore that the FA-based GPC is more suitable to carbonation in an atmospheric environment.

Hai Yan et Al (2014) An experimental work is done on GP binders by composing of MK and FA and Compared with to Control concrete. The Bending and compression tests were conducted at room temperature and later it is exposed to high temperature .It was found that at $50 \%$ mk-50\% FA GP paste, motor, concrete provides optimum bending and compressive strength as that of control mixtures both at room temperature and later exposure to high temperature. Strength increases upto 100 degs beyond which it is decreasing.

A.Z. Mohd et Al (2017) An experimental work is done on GPC panels and cylinders to test the effect of hydrocarbon fire exposure on the residual compressive strength characteristics. The Gladstone FA was used as the binder whilst the alkaline solution/FA ratio of 0.4 and NS/NH of 2.5. From test data, the compressive strength of $64 \mathrm{MPa}$ is taken for the experiment, with two different cylindrical specimens for 120 minutes was exposed on each side to the hydrocarbon fire whilst panels on one side for the same time duration. It was observed when GPC exposed to a hydrocarbon fire there are no symptoms of spalling and after fire exposure, the residual strength of $60 \%$ was maintained. Due to the low thermal conflict, the GP has excellent fire resistance.

Albitar et Al (2016) In this paper a study on a wide-ranging of the bond between reinforcement and GPC including an investigation of the influence of corrosion is made 102 pullout test specimens covering a range of parameters including bar diameter, concrete cover-to-diameter ratio, compressive strength, and level of corrosion are conducted it was found that the bond between reinforcement and GPC is stronger than that between reinforcement and OPC.

\section{B. Class-C Fly ash based Geopolymer Concrete:}

Chindaprasirt et Al (2011) An investigation was done with FA-C based GP mortar to study the effect of setting time of GP paste with the three different varieties of FA like Coarse original FA, Medium finesse FA and Fine FA and used heat curing and activated with $\mathrm{NH}$ and NS solutions to find setting time of paste, workability, drying shrinkage and strength characteristics with various varieties of FA . To improve workability a small amount of water is added. It was observed that with an increase in the FA fineness the initial setting time is decreasing but with fine FA and air-classified fine FA the flow properties, strength, and drying shrinkage properties of mortars were improved using fine FA.

Xueying et Al (2013) An experimental work is done using FA-C, the GP pastes and GP mortars are made at mass ratios of water-to-FA from 0.30 to 0.35 and studied workability, compressive strength and microstructure. It was observed that as More Water/FA ratio decreases the Fluidity and paste of GP. At $70^{\circ} \mathrm{C} 24 \mathrm{hrs}$ both paste and motor have the same compressive strength but with W/FA compressive strength of paste will be less compared to the motor. SEM analysis reported that the Dense structure of motor and paste will have compressive strength.

Pattanapong et Al (2014) An experimental work is done using FA-C with an alkaline solution to FA ratio of 0.5 , various $\mathrm{NH}$ molarities like $10 \mathrm{M}, 15 \mathrm{M}, 20 \mathrm{M}, \mathrm{NS} / \mathrm{NH}$ of 1.0 and 2.0, and cured in two ways like oven curing and ambient curing. It was observed the initial setting time of FA-C is 28 to 58. minutes. The strength and modulus of elasticity are increasing with an increasing $\mathrm{NH}$ molarity . Compare to present design code, the compressive, bond and splitting tensile strength is high for FA-C based GPC.

Gaurav Nagalia et Al (2016) An experimental work is done by using FA-C and FA-F of GP with different alkaline of $\mathrm{KH}, \mathrm{NH}, \mathrm{Ba}(\mathrm{oh}) 2$ and $\mathrm{LiOH}$ solutions. Different curing methods are used like Oven, Steam and room temperature and then tested for compressive strength. Microstructure recognizes the new phases formed in the GP matrix. it was observed that the microstructural of FA particles and calcium content have a significant effect on the setting time and the compressive strength of GPC, and the structure of the formed GP is typically glasslike. Compared with other alkali hydroxides the $\mathrm{NH}$ showed the high compressive strength.

\section{Hybrid based Geopolymer Concrete:}

The term is Hybrid defined as a mixture of two or more very different material's is known as Hybrid.

A waste Inorganic materials from thermal power stations with rich in Al-Si is used for making GPC but it is used for the precast application (Aleem and Arumairaj (2012); Hardjito and Rangan 2005) To convert this GPC for insitu application a partial replacement of rich AL-Si by different high calcium materials (Li et al. 2010; Pattanapong et al 2014; Pradip and Prabir 2015; William Gustavo et al 2016; Najif et al 2018; Elchalakani et al 2018; Hilal ElHassan and Said Elkholy 2019) like

a. FA-F and percentage of GGBS replaced with FA-F.

b. FA-F and percentage of cement replaced with FA-F

c. FA-F and partial replacement with other high calcium material materials can be used. 


\section{Recent Advancements in Geopolymer Concrete using Class-F and Class-C Fly Ash}

a.

\author{
Class-F fly ash and percentage of GGBS \\ replaced with Class-F fly ash:
}

Krishnaraja et Al (2014) An experimental investigation on the mix proportions and on the density and compressive strength of GPC with various percentages of GGBS replaced in FA-F at $14 \mathrm{M} \mathrm{NH}$ concentration and Strengths are calculated at 7 days and 28 days. It was observed that up to $50 \%$ replacement of GGBS in FA-F produced better mechanical properties but decreasing setting time, workability and slump value.

Pradip Nath et Al (2014) An experimental work is done on the effects of blending GGBFS with FA-F in the binder of GPC at $10 \mathrm{M}$ NH cured at room temperature. It was observed that the increase of GGBS results in workability decrease and increases strength similar to OPC concrete. Strength Gain slows down after 28 days.

Mohammed Haloob et Al (2016) An experimental work is done using FA-F and GGBS mixture and cured under ambient curing and studied on the mechanical and microstructural characteristics of GPC mixes. It was observed that over curing or steam curing can be avoided by partial replacement of FA-F with GGBS. The compressive, Flexural and tensile strength of GP is increasing by replacing FA-F with GGBS of 40 to $50 \%$. Through Microstructural analysis, a dense structure is observed by adding large content of GGBS

Rasoul et Al (2017)An experimental examination of Fly ash and various partial replacement Slag is done with different relative amounts $\mathrm{NH}$ solution at different concentrations of curing times and curing. The unit weight and uniaxial compressive strength (UCS) of the GP specimens were measured It was observed that due to slag the initial water content decreeing in GPC. The increase of NH solution up to $15 \mathrm{M}$ the UCS of FA:SG:50:50 based GP increases. The $70 \%$ strength is achieved within 2 days after 7 days there is no strength gained.

Najif et Al (2018) In this paper GP mortar mixes like Geopolymer mortar(GPM) and light weight Geopolymer concrete(LGPC).LGPC is prepared based on optimum mix design obtained using desert sand and studied on the effect of different mixing variables, including binding materials, curing temperature, and AA solution composition and content, on the rheological and mechanical performance It was observed that higher slag content faster polymerization reaction and shorter setting times the flow GPM was reported in the range of $49-150 \%$. The flow reduced with increasing slag content in the mixture. FA replacement $25 \%$ by slag showed the highest compressive strength irrespective of curing temperature. LGPC behaviors' like brittle material due to light weight aggregate.

Mahmoud Abo et Al 2018 An experimental investigation on the effects of various quantities of activator on the workability and early-age strength of A-A municipal slagFA-based GP mortar. Early-age compressive strength is measured under different curing conditions: steam curing, water curing \& air curing. Also, early-age splitting tensile flexural strength and SEM are examined for steam-cured mortar. it was found that both the curing regime and activator content in the main binder are significant factors influencing the performance evaluation of fresh mixtures and early-age strength of GPM. to predict the compressive strength a standard design equation is used As per ACI 209 codebook, and predications of splitting tensile and flexural strength of GPM are calculated using another standard.

William Gustavo et Al (2016) A durability study on GPC based on the mixture of FA with GBFS in an 80:20 ratio. Both FA/GBFS concrete and Control concrete were immersed in $5 \%$ by weight sodium sulfate and magnesium sulfate solutions. Measured Volumetric expansion, mechanical resistance loss, and Microstructure. It was observed that compared to control concrete the GPC 80:20 was less harmed by sodium sulfate and the mechanical properties increasing. A High deterioration of materials is found with the magnesium sulfate and loss of mechanical properties, expansion percentage is negligible for GPC.

\section{b. Class-F fly ash and percentage of cement replaced with Class-F fly ash:}

Pradip et Al (2015) An experimental study is done of FA-F based GPC fit for in-site curing condition by a little amount of OPC was added with FA-F and cured in-room temperature.it was observed that Workability and initial, Final setting time reduced compared to normal GPC. The Compressive strength is decreasing at 5\% OPC. Microstructure images have shown Calcium-rich hydration gel by adding OPC.

Ali A et Al (2016) An experimental investigation is done on FA-F based GPC to study the influence of FA content, additional OPC alkaline solution resting time, curing period and curing temperature and workability, compressive and splitting tensile strength, modulus of elasticity, water absorption, and thermal gravimetric analysis(TGA).it was observed that Mechanical properties are increasing by partial addition of cement but workability decreasing and weight loss decreasing by increasing temperature by TGA test.The $30 \mathrm{mins}$ NH solution has more workability and mechanical properties compared to $24 \mathrm{hrs}$ resting solution.

Ankur et Al (2016) An Experimental investigation is done on the properties of FA-F-based GPC in which FA-F was partially replaced with OPC. The workability, compressive strength, split tensile strength and rapid chloride permeability up to the age of 28 days are examined. It was noted that the workability of FA-F based GPC reduced with an increase in OPC content. Further, the addition of OPC, the compressive strength is increasing and permeability is decreasing at all ages, the best results were achieved for GP with $20 \%$ OPC. The microstructural analysis confirmed the variations in matrix making it denser, compact and less permeable.

Sudhakar et al (2018) A comparative study of flexural behavior of beam with RCC and GPC beams with $6 \%$ replacement of FA-F by GGBS and $6 \%$ replacement of FA by cement it was observed that compared to partial replacement of GGBS in GPC beam the partial replacement cement-based GPC beam gives better results in compressive strength as well as in flexure and setting time is also reduced and confirms that small amount of deflection and high moment of resistance than that of the GGBS based GPC beam. 
c.

\section{Class-F Fly ash and with other high calcium material by partial replacement Fly ash:}

Peem et al (2017) An experimental investigation is done to improve the mechanical characteristics and durability characteristics of recycled aggregate Geopolymer concrete(RAGPC) by adding cement and Nano silica shoes greater potential to develop the mechanical and durability characteristics of RAGPC

Jean-Baptiste et al (2017) An experimental study is done by adding partial and full replacement of FA with decomposite granite(CDG) and conducted tests on cubes It was observed that With $100 \%$ CDG in GPC a geopolymerization is happening and by partial replacement of FA in CDGGPC a higher strength is getting. Therefore Complete CDG can be used as a GP source element.

\section{Field applications of Geopolymer Concrete:}

Geopolymer concrete is increasingly used in the Field during the present decades.

- Repair of Tunnel-Lining Structure through A-A mortar. (Rui Chen et.al 2019)

- GPC slab has a better structural performance with static and dynamic loading and blast loadings as compared to Portland cement concrete slab. (Qingfei et Al 2019).

- GP brick models are prepared and 9Mpa compressive strength is achieved (Sh.K. Amin et al 2017).

- $\quad$ GPC the risk of excessive cracking is reduced by Powder metallurgy and sintering (Liew Yun-Ming et al 2017).

- GP interlocking bricks by with fine aggregate as crumb rubber was classified as non-effloresced and classified as third-class bricks and used as nonload-bearing material ( Peem et al 2018).

- GPC shows Good weathering resistance (Wei-Hao Lee et al 2019; D.V. Reddy et al 2013; William Gustavo et al 2016; Pasupathy et al 2018).

\section{CONCLUSION:}

Based on the literature review it is clear, that the study was done using FA-F as source material to find short term properties, long term properties and microstructure properties of GPC. The same properties are studied for FA-F based GPC by adding different types of fibers. Many research attempts are made using FA-Fas source material by partial replacement with rich Cao materials like GGBS, Portland cement, Calcium Carbonate (CaCO3), etc, for the In-situ applications.

It is seen that no systematic study was done for FA-C based GPC. With FA-C as source material in GPC, the short term, long term properties, and microstructure need to be investigated. FA-C with other partial replacement of highly rich calcium elements and with different kind fibers need to be investigated.

\section{REFERENCES:}

1. J.G.J. Olivier, G. Janssens-Maenhhout, M. Muntean, J.A.H.W. Peters, Trends in Global CO2 Emissions; 2015 Report, PBL Netherlands Environmental Assessment Agency, The Hague, Netherlands, 2015.
2. Davidovits, J. "High-alkali Cements for 21st Century Concretes. Concrete Technology: Past, Present and Future". P. K. Mehta, ACI, Detroit, USA. 1994 SP 144-19: 383-397.

3. Hardjito, D. and Rangan, B. V. (2005), Development and Properties of Low-Calcium Fly Ash-based Geopolymer Concrete, Research Report GC1, Faculty of Engineering, Curtin University of Technology, Perth, available at espace @ curtin or www.geopolymer.org.

4. Wallah, S. E., and Rangan, B. V. "Fly ash-based geopolymer concrete.” Research Rep. GC 4, (2006). Curtin Univ. of Technology, Perth, Australia.

5. Li, C., Sun, H., and Li, L. (2010).“A review: The comparison between alkali-activated slag $(\mathrm{Si} / \mathrm{Ca})$ and metakaolin $(\mathrm{Si} / \mathrm{Al})$ cements." Cem Concr. Res., 40(9), 1341-1349.

6. Hassan; and Said Elkholy. "Performance Evaluation and Microstructure Characterization of Steel Fiber-Reinforced AlkaliActivated Slag Concrete Incorporating Fly Ash". DOI 10.1061/(ASCE)MT.1943-5533.0002872. (C) 2019 American Society of Civil Engineers.

7. Hilal El-M.I. Abdul Aleem and P.D. Arumairaj.(2012) "Optimum mix for the geopolymer concrete". Indian Journal of Science and Technology Vol. 5 No. 3 ISSN: 0974- 6846.

8. Raijiwala D.B.1 Patil H. S (2011). "Geopolymer Concrete: A concrete of next decade" Journal of Engineering Research and Studies. E-ISSN 0976-7916

9. Benny Joseph, George Mathew. "Influence of aggregate content on the behavior of fly ash based geopolymer concrete". Scientia Iranica A (2012) 19 (5), 1188-1194.

10. M.I. Abdul Aleem, P.D. Arumairaj, S. Vairam . " Chemical Formulation of Geopolymer Concrete with M-Sand". International Journal of Research in Civil Engineering, Architecture and Design Volume 1, Issue 2, October-December, 2013, pp. 54-60, (C) IASTER .

11. Ali A. Aliabdo, Abd Elmoaty M. Abd Elmoaty a, Hazem A. Salem. "Effect of water addition, plasticizer and alkaline solution constitution on fly ash-based geopolymer concrete performance".Construction and Building Materials 121:694-703

12. Lateef SeyedAli Ghahari, Edward (Eddie) Deaver, Davis Leaphart Paul Ziehl(2016), "Investigation of early compressive strength of fly ash-based geopolymer concrete at ambient conditions. Construction and Building Materials 112:807-815.

13. Ernesto J. Guades. "Experimental investigation of the compressive and tensile strengths of geopolymer mortar: The effect of sand/fly ash (S/FA) ratio". Construction and Building Materials 127 (2016) 484493.

14. Chamila Gunasekara; Sujeeva Setunge; DavidW.Law; NickWillis; Burt(2018). "Engineering Properties of Geopolymer Aggregate Concrete". American Society CivilEngineers.DOI:10.1061/(ASCE)MT.1943-5533.0002501.

15. D. Madhu Raj, J.V. Narasimha Raju, M. Suneel. "An Experimental Study On Effect Of Partial Replacement Of Normal Weight Aggregates With Lightweight Aggregates In Flyash Based Geopolymer Concrete". International Research Journal Of Engineering And Technology (IRJET) 2018.

16. Manoj kumar k, and ramasubramani. "Experimental study on the behaviour of torsion In geopolymer concrete beams with steel fibers".Jr. of Industrial PollutionControl. Research article 33(S2)(2017) pp 1294-1299.

17. Pradip Nath , Prabir Kumar Sarker. "Flexural strength and elastic modulus of ambient-cured blended low-calcium fly ash GPC". Construction and Building Materials 130 (2017) 22-31

18. M. Venu, T. D. Gunneswara Rao. "An Experimental Investigation of The Stress-Strain Behaviour Of Geopolymer Concrete". Slovak Journal of Civil Engineering 2018 Vol. 26, 2018, No. 2, 30 - 34.

19. Chen yang and Rishi Gupta."Prediction of the Compressive Strength from Resonant Frequency for Low-Calcium Fly Ash-Based Geopolymer Concrete". DOI: 10.1061 /(ASCE)MT. 1943-5533. 0002228. (C) 2018 American Society of Civil Engineers.

20. Salmabanu Luhar,Sandeep Chaudhary, Ismail Luhar. "Thermal resistance of fly ash based rubberized geopolymer concrete". Journal of Building Engineering 19 (2018) 420-428

21. Wei Li and Hongjian Du." Properties of PVA Fiber Reinforced Geopolymer Mortar 2018,DOI: 10.1007/978-3-319-78175-4_71. 


\section{Recent Advancements in Geopolymer Concrete using Class-F and Class-C Fly Ash}

22. Kirubajiny Pasupathy; Marita Berndt; Jay Sanjayan; Pathmanathan Rajeev; and Didar Singh Cheema. "Durability Performance of Precast Fly Ash-Based Geopolymer Concrete under Atmospheric Exposure Conditions". DOI: 10.1061/(ASCE)MT.1943-5533.0002165. (C) 2018 American Society of Civil Engineers.

23. Hai Yan Zhang, Venkatesh Kodur, ShuLiang Qi,Liang Cao,Bo Wua, "Development of metakaolin-fly ash based geopolymers for fire resistance applications". Construction and Building Materials 55 (2014) 38-45.

24. A.Z. Mohd Ali, Jay Sanjayan, Maurice Guerrieri. "Performance of geopolymer high strength concrete wall panels and cylinders when exposed to a hydrocarbon fire". Construction and Building Materials 137 (2017) 195-207.

25. M. Albitar; P. Visintin; M. S. Mohamed Ali; O. Lavigne4; and E. Gamboa. "Bond Slip Models for Uncorroded and Corroded SteelReinforcement in Class-F Fly Ash GPC". DOI: 10.1061/ (ASCE) MT. 1943-5533.0001713. (C) 2016 American Society of Civil Engineers..

26. P.Chindaprasirt; T. Chareerat; S. Hatanaka; and T. Cao. "HighStrength Geopolymer Using Fine High-Calcium Fly Ash". DOI: 10.1061/ (ASCE) MT.1943-5533.0000161. (C) 2011 American Society of Civil Engineers.

27. Xueying Li, Xinwei Ma, Shoujie Zhang and Enzu Zheng "Mechanical Properties and Microstructure of Class C Fly Ash-Based Geo polymer Paste and Mortar”. Materials ISSN 1996-1944,2013

28. Pattanapong Topark-Ngarm; Prinya Chindaprasirt2; and Vanchai Sata. "Setting Time, Strength, and Bond of High-Calcium Fly Ash Geopolymer Concrete". DOI: 10.1061 /(ASCE) MT .1943 -5533 .0001157. (C) 2014 American Society of Civil Engineers.

29. Gaurav Nagalia; Yeonho Park; Ali Abolmaali; and Pranesh Aswath. "Gaurav Nagalia1; Yeonho Park, Ph.D., M.ASCE2; Ali Abolmaali, Ph.D., M.ASCE3; and Pranesh Aswath”. DOI: 10.1061 /(ASCE) MT .1943-5533.0001656. (C) 2016 American Society of Civil Engineers.

30. Gaurav Nagalia1; Yeonho Park; Ali Abolmaali; and Pranesh Aswath "Gaurav Nagalia1; Yeonho Park, Ph.D., M.ASCE2; Ali Abolmaali, Ph.D., M.ASCE3; and Pranesh Aswath". DOI: 10.1061/ (ASCE) MT. 1943-5533.0001656. (C) 2016 American Society of Civil Engineers.

31. A.R.Krishnaraja,N.P.Sathishkumar,T.Sathish,KumarP.DineshKmar. "Mechanical Behaviour of GPC under Ambient Curing". IJSET 2014 Volume No.3 Issue No.2, pp : 130 - 132.

32. Pradip Nath, Prabir Kumar Sarker. "Effect of GGBFS on setting, workability and early strength properties of fly ash GPC cured in ambient condition" Construction and Building Materials 66 (2014) 163-171

33. Rasoul Shadnial and Lianyang Zhang, P.E., M. "Experimental Study of Geopolymer Synthesized with Class F Fly Ash and Low-Calcium Slag”. DOI: 10.1061/(ASCE)MT.1943-5533.0002065. (C) 2017 American Society of Civil Engineers.

34. Najif Ismail and Hilal El-Hassan, M. "Development and Characterization of Fly Ash-Slag Blended Geo polymer Mortar and Lightweight Concrete." DOI: 10.1061/(ASCE)MT.19435533.0002209. (C) 2018 American Society of Civil Engineers

35. Mahmoud Abo El-Wafa and Kimio Fukuzawa. "Early-Age Strength of Alkali-Activated Municipal Slag-Fly Ash-Based Geopolymer Mortar”. DOI: 10.1061/(ASCE)MT.1943-5533.0002209. (C) 2018 American Society of Civil Engineers.

36. William Gustavo Valencia Saavedra; Daniela Eugenia Angulo;and Ruby Mejía de Gutiérrez."FlyAsh Slag Geopolymer Concrete: Resistance to Sodium andMagnesium Sulfate Attack". DOI 10.1061/(ASCE)MT. 1943-5533. 0001618. (C) 2016 American Society of Civil Engineers.

37. Pradip Nath , Prabir Kumar Sarker. "Use of OPC to improve setting and early strength properties of FA-F GPC cured at room temperature". Cement \& Concrete Composites 55 (2015) 205-214.

38. Ali A. Aliabdo , Abd Elmoaty M. Abd Elmoaty, Hazem A. Salem. "Effect of cement addition, solution resting time and curing characteristics on fly ash based geopolymer concrete performance". Construction and Building Materials (2016) 123:581-593.

39. Ankur Mehta , Rafat Siddique . "Strength, permeability and microstructural characteristics of low-calcium fly ash based geopolymers". Construction and Building Materials 141 (2017) 325-334

40. K Sudhakarreddy, Srinivas Angadi, B Sivakondareddy, T Chandrasekharreddy and Venu Malagavelli. "Flexural behaviour of cement added geopolymer concrete". 14th International Conference on Concrete Engineering and Technology (2018) 092003 doi: 10.1088 /1757 -899X / 431/9/092003.

41. Peem,Nuaklong,VanchaiSata ,Ampol Wongsa, Korb Srinavin, PrinyaChindaprasirt. "Recycled aggregate high calcium fly ash GPC with inclusion of OPC and nano-SiO2". Construction and Building Materials 174 (2018) 244-252.
42. Jean-Baptiste Mawulé Dassekpo, Xiaoxiong Zha, Jiapeng Zhan "Compressive strength performance of geopolymer paste derived from Completely Decomposed Granite (CDG) and partial fly ash replacement”. Construction and Building Materials 138 (2017) 195203

43. Sh.K. Amin , S.A. El-Sherbiny , A.A.M. Abo El-Magd, A. Belal, M.F. Abadir. "Fabrication of geopolymer bricks using ceramic dust waste". Construction and Building Materials 157 (2017) 610-620.

44. Liew Yun-Ming, Heah Cheng-Yong a, Long-yuan Li , Nur Ain Jaya , Mohd Mustafa Al Bakri Abdullah,Tan Soo Jin, Kamarudin Hussin."Formation of one-part-mixing geopolymers and geopolymer ceramics from geopolymer powder". Construction and Building Materials 156 (2017) 9-18

45. Bashar S Mohammeda,*, Mohd Shahir Liewa, Wesam S Alaloula, Amin Al-Fakiha, Wadhah Ibrahima, Musa Adamu. "Development of rubberized geopolymer interlocking bricks". Case Studies in Construction Materials 8 (2018) 401-408.

46. Qingfei Menga, Chengqing Wua, Yu Sub, Jun Lia, Jian Liua, Jiabao Pangb. "Experimental and numerical investigation of blast resistant capacity of high performance geopolymer concrete panels". Composites Part B 171 (2019) 9-19.

47. Wei-Hao Lee, Jhi-Hao Wang, Yung-Chin Ding, Ta-Wui A study on the characteristics and microstructures of GGBS/FA based geopolymer paste and concrete". Construction and Building Materials 211 (2019) 807-813.

48. Rui Chen; Hongpeng Lai; Da Cui; and Yue Zhu. "Alkali-Activated Mortar for Tunnel-Lining StructureRepair".DOI:10.1061/(ASCE)MT.1943-5533.0002857. @ 2019 American Society of Civil Engineers.

\section{AUTHORS PROFILE}

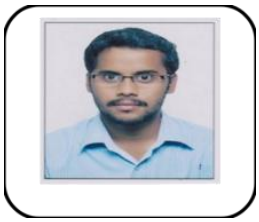

\section{First Author}

B. Vijaya Prasad. Research scholar, Department of Civil Engineering, Karunya Institute of technology and sciences, Coimbatore Tamilnadu, India. He has obtained his Bachelor's Degree in Civil Engineering from JNTUH College of Engineering Hyderabad in the year 2014, Telangana India. Master's Degree in Structural and Construction Engineering from Kakatiya Institute of Technology and Science, Warangal, in the year 2016 Telangana, India. He has 1year 4 months of teaching experience. He has published 2 papers in international journals.

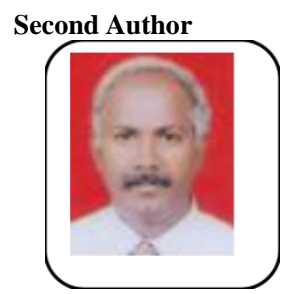

Dr. P. D. Arumairaj, Professor in Civil Engineering, Karunya Institute of Technology and science, Coimbatore -13 , India. He has obtained his Bachelors Degree in Civil Engineering from Regional Engineering College, Trichy in the year 1983, Master's Degree in Geotechnical Engineering from Govt. College College of Technology, Coimbatore in the year 1989 and Doctorate Degree in the year 2006, under Bharathiyar University, Coimbatore. He has 35 years of Teaching experience. He has published more than 100 papers in National and International Journals. He has produced 4 Ph.D. scholars and 8 scholars are pursuing under his guidance .He has guided 86 M.E project thesis. He is also a practicing consultant. He has effectively design and executed buildings and infrastructure projects. 